\title{
Recovery and validation of historical sediment quality data from coastal and estuarine areas: an integrated approach
}

\author{
Frank T. Manheim*, Marilyn R. Buchholtz ten Brink, Ellen L. Mecray \\ U.S. Geological Survey, Center for Coastal and Marine Geology, Woods Hole, MA 02543, USA
}

Accepted 22 June 1998

\begin{abstract}
A comprehensive database of sediment chemistry and environmental parameters has been compiled for Boston Harbor and Massachusetts Bay. This work illustrates methodologies for rescuing and validating sediment data from heterogeneous historical sources. It greatly expands spatial and temporal data coverage of estuarine and coastal sediments. The database contains about 3500 samples containing inorganic chemical, organic, texture and other environmental data dating from 1955 to 1994. Cooperation with local and federal agencies as well as universities was essential in locating and screening documents for the database. More than $80 \%$ of references utilized came from sources with limited distribution (gray literature). Task sharing was facilitated by a comprehensive and clearly defined data dictionary for sediments. It also served as a data entry template and flat file format for data processing and as a basis for interpretation and graphical illustration. Standard QA/QC protocols are usually inapplicable to historical sediment data. In this work outliers and data quality problems were identified by batch screening techniques that also provide visualizations of data relationships and geochemical affinities. No data were excluded, but qualifying comments warn users of problem data. For Boston Harbor, the proportion of irreparable or seriously questioned data was remarkably small $(<5 \%)$, although concentration values for metals and organic contaminants spanned 3 orders of magnitude for many elements or compounds. Data from the historical database provide alternatives to dated cores for measuring changes in surficial sediment contamination level with time. The data indicate that spatial inhomogeneity in harbor environments can be large with respect to sediment-hosted contaminants. Boston Inner Harbor surficial sediments showed decreases in concentrations of $\mathrm{Cu}, \mathrm{Hg}$, and $\mathrm{Zn}$ of 40 to $60 \%$ over a 17-year period. (c) 1998 Elsevier Science B.V. All rights reserved.
\end{abstract}

Keywords: geochemical databases; quality screening; contaminated harbor sediments; historical data; Boston Harbor; Massachusetts Bay

\section{Introduction}

This paper reports new methodologies to compile sediment quality databases from historical, heterogeneous data sources. The primary test area for this work was the Boston Harbor-Massachusetts Bay area (Fig. 1). Sediments in Boston Harbor are highly

\footnotetext{
$\bar{*}$ Corresponding author.
}

contaminated, and some of its influence has spread into Massachusetts Bay, partly through transport by tidal and other current movements, and partly due to transport of dredged harbor sediments to offshore disposal sites. The development since 1985 of new treatment facilities and an offshore outfall, under the direction of the Massachusetts Water Resources Authority (MWRA), has been accompanied by additional sampling and monitoring (MWRA, 1997). The 


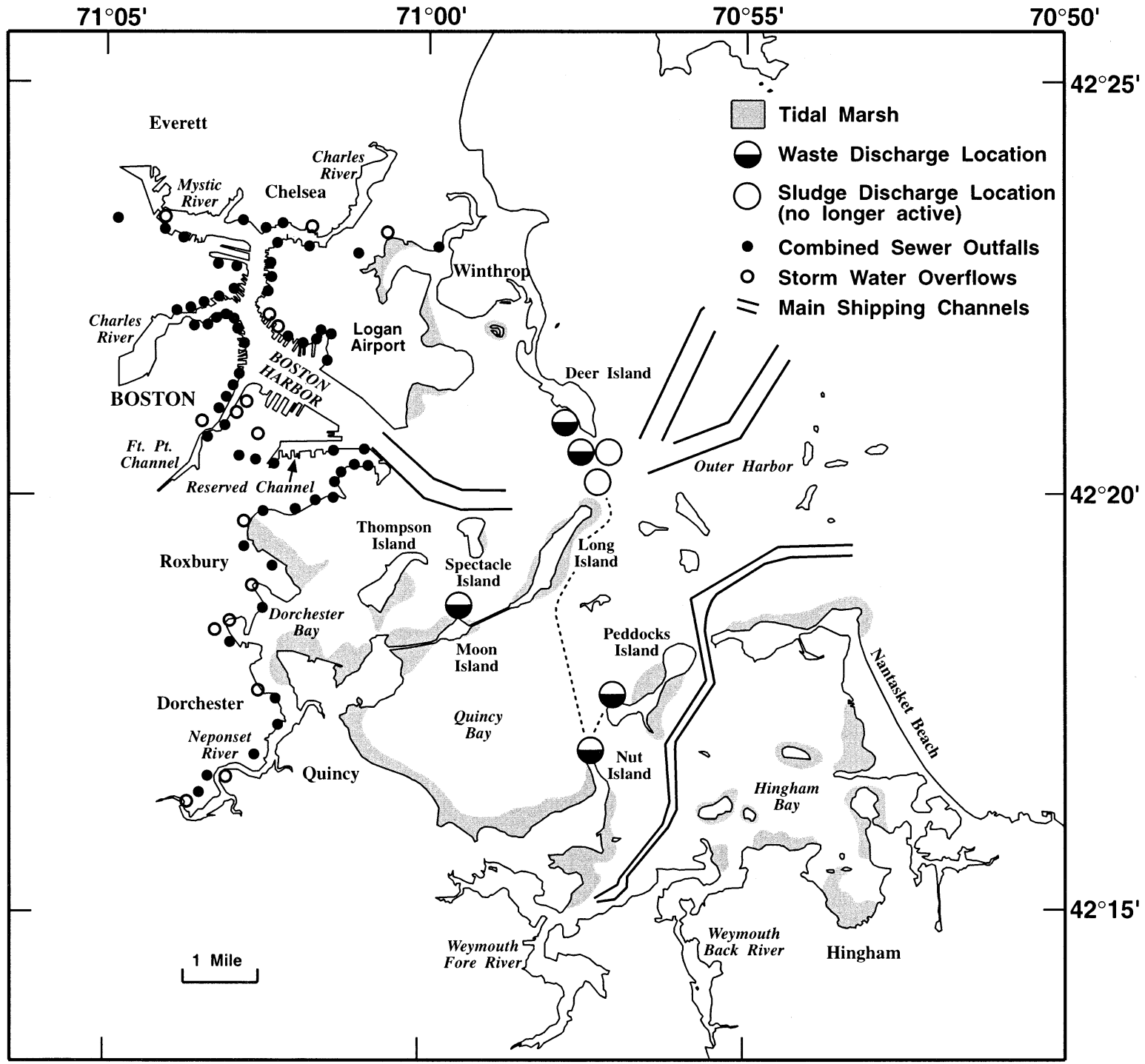

Fig. 1. Location map for Boston Harbor. Sewage effluent outfalls, combined sewer overflows (CSOs) and sediment sampling points.

current work was performed as a part of U.S. Geological Survey (USGS) cooperation with MWRA and other organizations on Boston Harbor contaminant impacts (Butman et al., 1992; Bothner et al., 1994).

In 1989 a National Research Council report (NRC, 1989) pointed out the scarcity of information about contamination in coastal and estuarine waters around the United States, but recommended against 'mapping' of contaminants in sediments. The reasons for this recommendation were not mentioned in the report; however, the complexity of compiling heterogeneous data and uncertainties about data comparability and quality were known to be factors of concern. Over the past decades many sediment and other environmental surveys with increasingly standardized quality control protocols have been performed. However, historical data from diverse sources were rarely incorporated in local and regional databases until USEPA responded to a congressional mandate to create a nation-wide inventory of sediment quality (USEPA, 1996). 
Notwithstanding the problems, justifications for compilation of quality-controlled heterogeneous data are strong. They include: (1) better definition and statistical control of the spatial distribution and heterogeneity of contaminants; (2) linkage of contaminants to data on bottom substrate type and morphology; (3) more informed decisions on when and where to use costly higher-tier measurement measurements (e.g. animal toxicity studies, acid-volatile sulfide and interstitial water analyses; USEPA, 1995 and references cited therein); (4) ability to use historical data as independent means of ascertaining changes in contaminant status with time; and (5) confirmation that concentrations of contaminants are low or within natural sediment variability (i.e. define not merely 'how dirty is dirty', but 'how clean is clean'). Definitive data provide more assurance to local populations than absence of information on presence of contamination.

At the onset of the work in Boston Harbor the total number of samples in an uncompleted database effort sponsored by USEPA for the area (Metcalf and Eddy, 1984; Mason, 1984) aggregated between 500 and 600 samples. This report cited 200 references. As a result of systematic collection, entry, and processing efforts outlined in this paper, we have been able to accumulate a total of about 3500 sediment samples from roughly 80 sources. The total number of literature citations in our reference list, which provides general environmental background data, is about 1600 (Scott, 1996; unpublished data). The techniques developed in this effort have since been applied to other coastal areas in ongoing studies, including the Gulf of Maine (Buchholtz ten Brink et al., database and manuscript in review; southern Louisiana (Manheim et al., 1997, and are in preparation for Long Island Sound and the New York Bight. Preliminary versions of results presented here were presented to workshops in preparation for a National Research Council panel report on contaminated sediments (NRC, 1997).

\subsection{Principles}

The main principles underlying the current work include: (1) cooperation among agencies and organizations to identify and compile data from diverse sources; (2) a comprehensive data dictionary; (3) use of widely accessible software and hardware; (4) data entry and batch screening techniques; and (5) data validation and quality control procedures.

\section{Methods and examples}

\subsection{Cooperation and sources of data}

Cooperation through shared expertise and resources is essential to insure both a thorough exploitation of dispersed existing data and knowledgeable interpretation and effective use of the compiled data. Earlier stages of the sediment database work were reported by Manheim and Hathaway (1991) and resulted in data exchanges with or transfer to the U.S. Environmental Protection Agency (USEPA), Region I, USEP's National sediment Inventory (NSI), and the U.S. Army Corps of Engineers (New England Division) (Buchholtz ten Brink et al., 1992; Manheim et al., 1992; Manheim, 1993).

Our search for references found that about $80 \%$ of the environmental research literature compiled for Boston Harbor-Massachusetts Bay (Scott, 1996; database in revision) consists of 'gray literature'. The proportion of samples supplying raw data for our chemical database in this category is still higher. Gray literature is here defined as research data that are available in limited-distribution documents such as non-serial, in-house and consultant reports, and unpublished papers and electronic data files. Citations to such work are often not included in abstracting services or library catalogs or accessions. Theses and dissertations are an intermediate publication type. They are valuable because they may report extensive raw data and describe methodologies in detail. Limiting the search to electronic media would have excluded more than three quarters of our present data set.

\subsection{Data dictionary}

A comprehensive and clearly defined data dictionary for sediments and operational parameters provided the data structure and data entry template for most data processing. The data dictionary incorporates station data and sediment parameters from our and other large national sediment databases. In our analytical (secondary-user) database version, the 
key referencing unit is the sediment sample, which is identified by a unique Reference ID number. These Reference ID numbers link data stored in six or more flat-file data tables containing: station data, inorganic data, organic chemical data (three files), and texture (grain size) data. Text fields provide descriptions or comments that define methods and quality-control parameters. Finally, supplementary tables contain information such as glossaries and organizational addresses. These data are meant to be self-explanatory insofar as possible. Comments relating to specific data are provided in fields adjacent to the data wherever possible to ensure proper use and transfer of the data.

The data dictionary in spreadsheet format, is suited for convenient hard-copy output. In 'vertical' format it lists field names vertically, with filenames in various lengths and full definitions provided in rows. For normal data entry and processing, the data dictionary is transposed into 'horizontal' mode. It can now serve as a data entry template and format for data processing and analysis. When data entry is completed, the flat file tables may be directly used for creating graphical and interpretive output. Examples of part of the station data and inorganic chemical data fields are provided in Tables 1 and 2. The data dictionary can be continuously updated (supplemented with new fields) at any time. Releases of the database are designed to always be accompanied by a current data dictionary.

\subsection{Database structure}

In computer database terms, operational structures (relational) are distinguished from analytical structures (flat file). Our data entry and processing, as well as output to graphical interpretation, are performed on flat files (spreadsheet software). The fields reflected in the data dictionary are designed to interface with the flat-file format. They contain redundancies, like alternative formats for location as latitude/longitude or state plane coordinates, and text. Redundancy is avoided in standard relational dbms's. It is deliberately used here in order that users can find fields in which to enter raw data in its original reported form and units. Qualifying fields are retained in the master tables to associate comments closely with data. These features expand the total number of fields (which can be increased as needed) to nearly 1000 , although only a small fraction of these is normally used in any data entry or analytical task. Given normal software field limits of 256 (Table 3), we have subdivided the total parameter (field) list into six linkable tables. A full bibliographic reference database is maintained in separate bibliographic software for searchability and transferability to desired editorial style.

The data structures used are similar to the flat file structures used in the NOAA National Standards and Trends program COSED data base (NST, 1994).

Working strategy has resemblances to the recently developed 'data mining' paradigm (Edelstein, 1997) for databases. In addition to permitting verification of existing hypotheses by querying databases, our databases are used to explore data relationships leading to new hypotheses, e.g. what internal relationships among concentrations of organic congeners are most consistent? Why? Unlike industrial 'data mining' systems, the operations proceed by manual rather than automated search operations. Data structures and procedures are therefore designed to make these operations as simple and convenient as possible.

\subsubsection{Database management software utilization}

Database management software (dbms), PARADOX $^{\mathrm{TM}}$ and ACCESS ${ }^{\mathrm{TM}}$, was used to accommodate large databases (e.g. bathymetric data and large sediment sample files), and data queries and perform transformations that cannot be accomplished using spreadsheets. This software was not utilized in true relational mode. True relational databases isolate semantically related multiple relationships and eliminate redundancies. They are required for very large data sets, and provide great flexibility in data manipulation and querying. The cost is that data structures become complex and nonintuitive for most persons and the systems require professionally trained data management specialists.

Thus, for the present systems greater aggregation of relationships (grouping of spreadsheet fields, as in the case of data qualifiers) is utilized than in standard dbms operations. Although this involves limitations, including increasing the number of data tables, it keeps software simple, and maintains the coherence of data groups in ways suited to work tasks. It facilitates flexible use of text and comment 


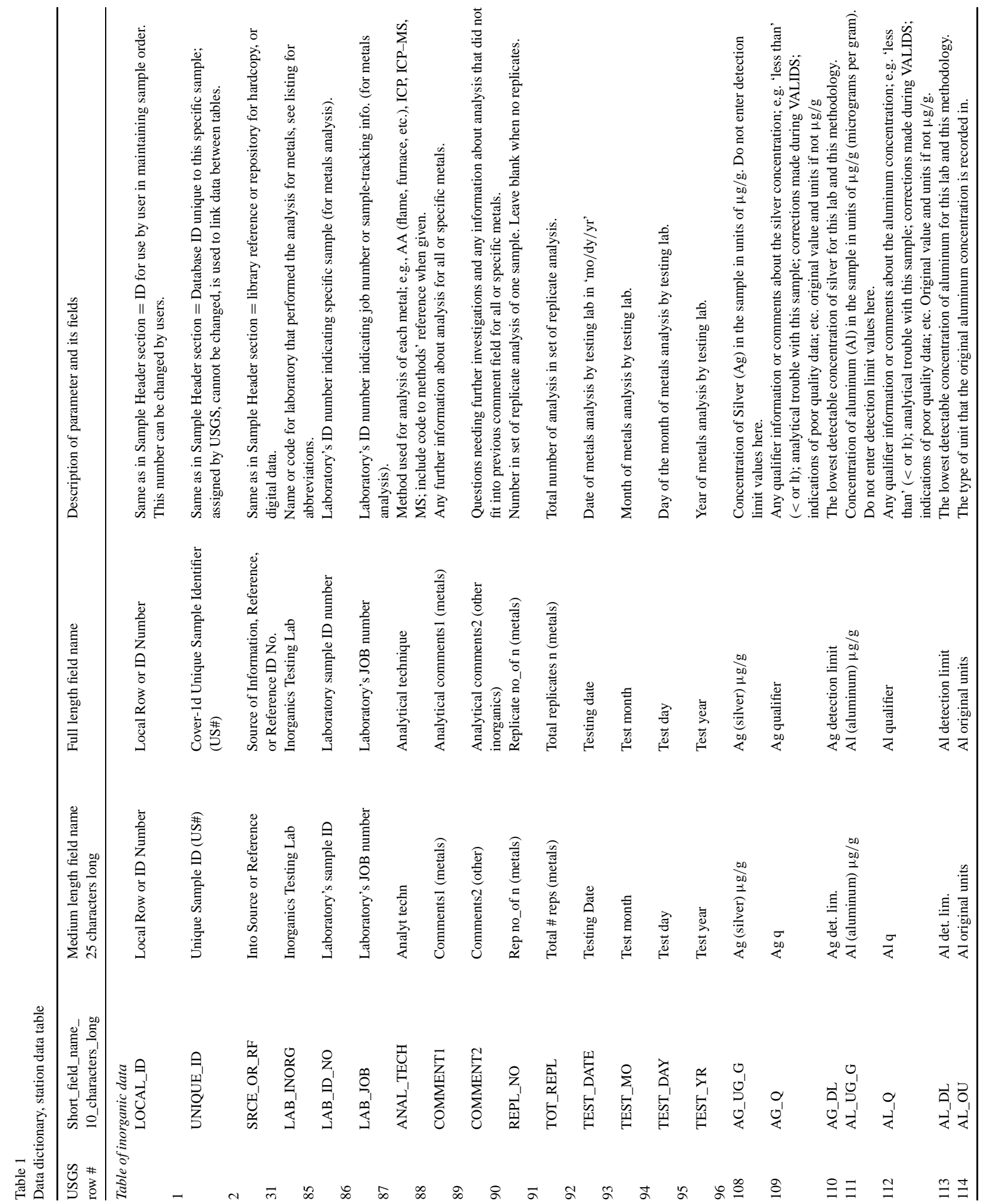




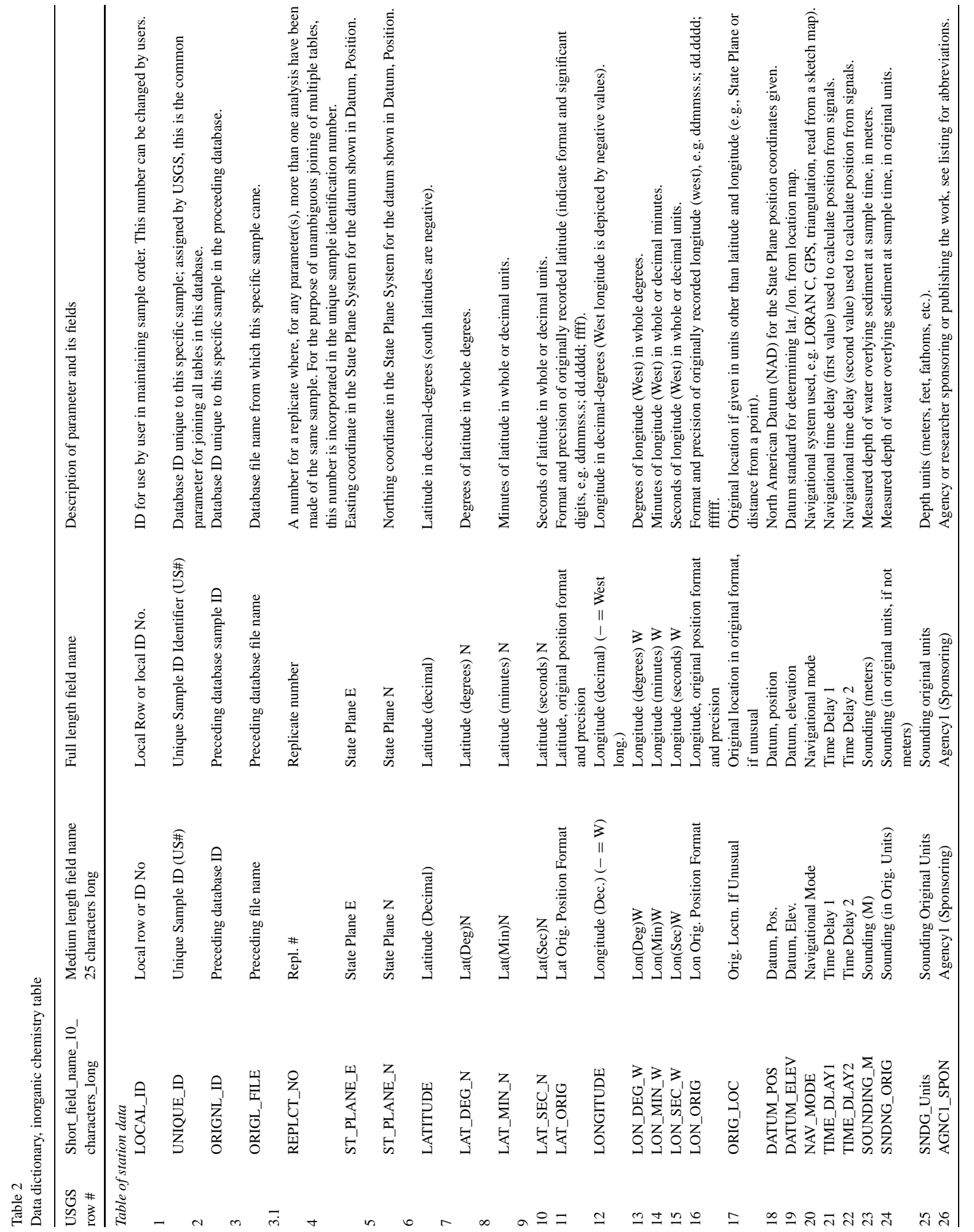


Table 3

Software limitations for desktop data management software

\begin{tabular}{llllll}
\hline Type & Number of records/table & Characters per record & No. fields & Characters per fieldname & Characters per field \\
\hline Dbms & 2 billion & 65,000 & 256 & $10^{\mathrm{a}-54}$ & $256^{\mathrm{b}}$ \\
Spreadsheet & $8,000-65,550^{\mathrm{c}}$ & $65,000-130,000$ & $256-512^{\mathrm{d}}$ & 256 & 256 \\
\hline
\end{tabular}

${ }^{\mathrm{a}}$ Older versions of $\mathrm{dBase}^{\mathrm{TM}}$. ${ }^{\mathrm{b}}$ Except memo fields, which have limited interactive capacity. ${ }^{\mathrm{c}} \mathrm{EXCEL}^{\mathrm{TM}}$ has increased from 16,000 to current 65,550 records. ${ }^{\mathrm{d}}$ LOTUS $123^{\mathrm{TM}}$ has a 512 field capacity. Alpha Five has a 128 field capacity.

fields, meaningful field headings, and minimizes the risk that data quality flags (critical for heterogeneous data sets) become separated from the analytical data.

\subsection{Data entry and screening}

References having data to be entered were prescreened by a scientist or environmental specialist, who noted the nature and quality of data to be entered and resolved problems about data definitions, gaps in coverage, units, sampling or analytical issues. After checking compatibility of field definitions and possible sample redundancy, data were encoded as fully as the completeness of original data sources allowed. When electronic data were involved, comparability of data fields and software data transfer formats was confirmed. The data dictionary mentioned previously provides comment fields for detection limit and data quality, which includes notes on nonstandard units. Fields are also provided for extended comments on data quality or documentation for each table and for special parameters (e.g. location methodology). References are entered in bibliographic software format, which allows output to be made in a variety of editorial styles, and makes electronic searches on annotations possible.

Original (raw) data are preserved wherever available. Transformations (e.g. location to decimal degrees) are provided in separate fields. This minimizes artifacts of conversion, and often provides useful information on the way data were prepared (e.g. rounding conventions).

Data processing typically goes on concurrently with further data entry. Checks on data consistency, sample designation, location and other station data may reveal clerical problems that can be corrected. Missing or incorrect locations are one of the more frequent problems or gaps in data. The most useful format for plotting locations is decimal latitudes and longitudes. Often, however, locations are given in degrees, minutes and seconds, state plane coordinates, or only in the form of location plots. The latter are converted to decimal degrees using standard conversion software. Location sketches are converted by optical scale matching equipment and standard base maps like USGS topographic maps or NOAA harbor charts, computer digitization, or manual equivalents. Data lacking specific locations are entered because these may be found in other documents, or more generally identified data may have value for characterizing larger data sets in spite of the absence of specific locations (e.g. frequency plots such as Figs. 2 and 3). Once data are entered from the reference they undergo quality/validation checks as summarized below.

\subsection{Data validation and quality control}

Data quality problems were identified by batch screening techniques since standard quality-assurance (QA/QC) protocols currently used for new sampling and laboratory analyses by federal and state agencies and firms that consult for them (Baker and Kravitz, 1992; USEPA, 1995) are usually inapplicable to historical data. Techniques included screening for outliers and comparison of data from diverse origins.

Early work in Boston Harbor demonstrated that common problems like sample identification, errors in unit designations, and gaps in location data were reparable (Manheim and Hathaway, 1991). Moreover, problems of analytical origin tended to occur in batches. Our quality control effort has therefore been directed toward establishing practical methods for identifying data that fall outside normal ranges of sample heterogeneity and analytical variability, i.e. deviate from internal relationships characteristic for well-controlled data. We use batch screening 


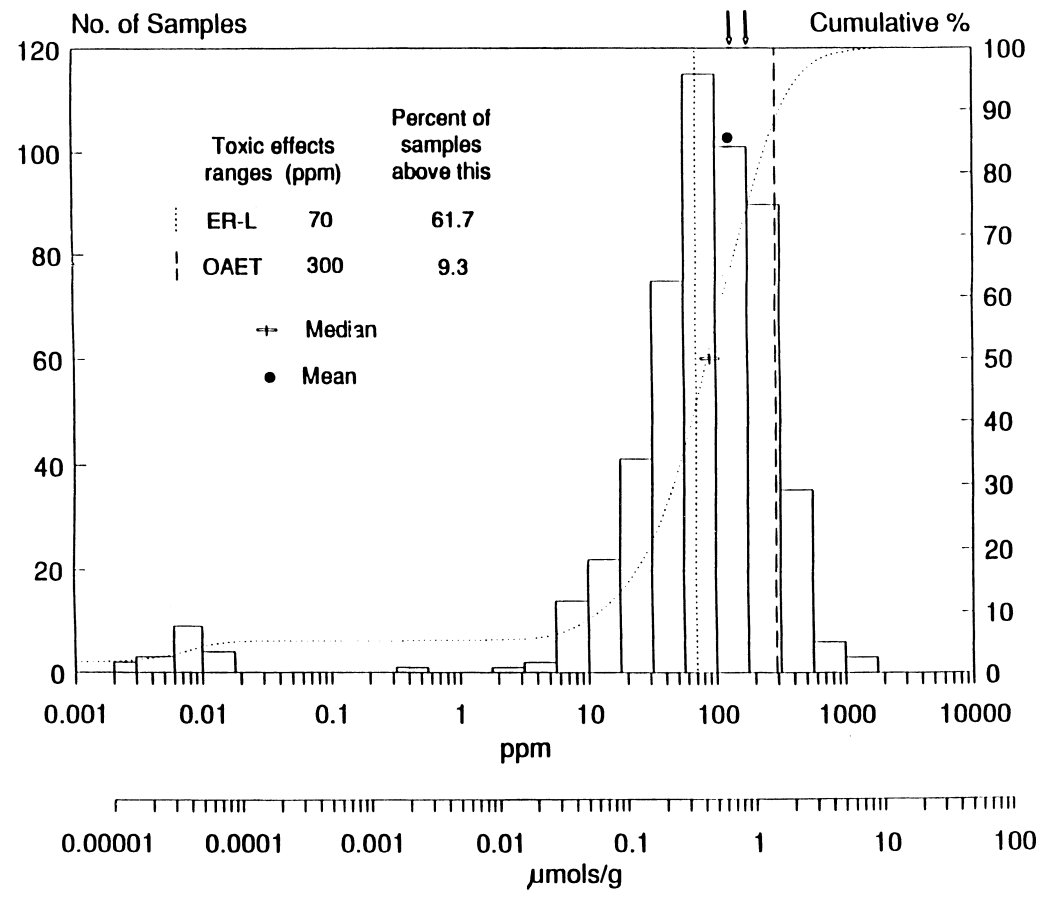

Fig. 2. Frequency plot of raw copper values in 'Boston Harbor Data Management File' (Manheim and Hathaway, 1991). Arrows along the top of the diagram show the values for the element at NS\&T monitoring sites in Boston Harbor. Curved dotted line is cumulative distribution. Dashed and dotted vertical lines refer to NS\&T apparent toxicity thresholds utilized by Long and Morgan (1990).

techniques referred to generally as a VALIDS procedure (Validation by Interactive Data Screening) to accomplish this task.

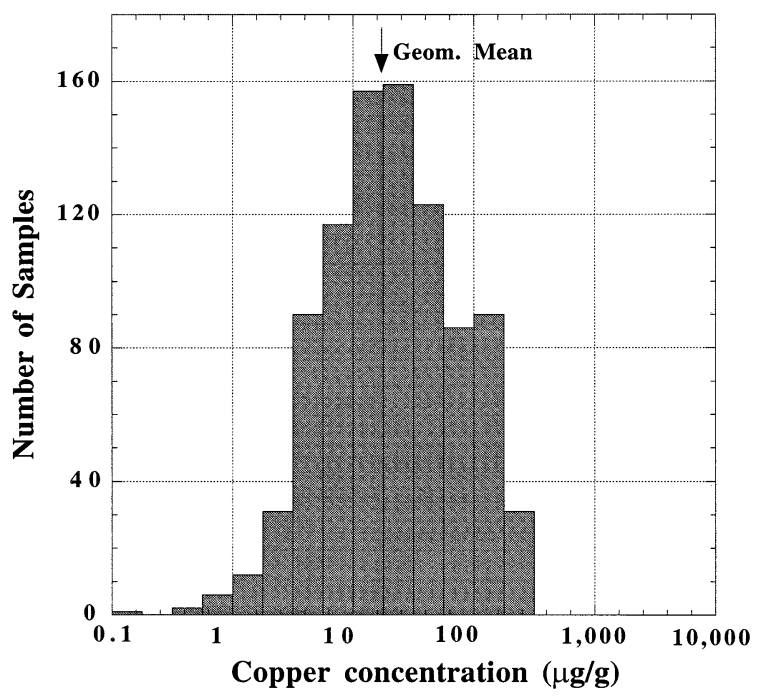

Fig. 3. Frequency plot of copper values in NOAA NS\&T benthic surveillance stations (NST, 1996).
We have chosen to retain all raw data in databases, regardless of problems associated with given data sets. Exclusion would involve arbitrary choices about data acceptability and uses. It might create unwarranted assumptions about the quality of data retained. Exclusion of seriously flawed data already available in the public record might result in other workers utilizing them without realizing that problems had already been encountered with them. We make an effort to retain data as originally reported and provide additional comments for the user when the data are repaired or identified as having questionable quality.

\section{Examples of display of geochemical parameters for quality validation}

\subsection{Frequency plots}

Trace elements in naturally occurring sediments and rocks have long been known to follow lognormal distributions of occurrence vs. concentration (Ahrens, 1954). Anthropogenic contaminant concen- 
trations in larger national data sets for sediments have likewise been observed to follow lognormal distributions (e.g. O'Connor, 1990). Histogram plots provide helpful delineation of the frequency of analytical data and reveal outlier groupings, and in some cases, problems in reporting of units (organic constituents). Points within these populations can be inspected to find explanations for the behaviors. Fig. 2 shows a plot of raw data for copper in sediments, processed from the earliest electronic data file for Boston Harbor (Manheim and Hathaway, 1991). This demonstrates the typical lognormal distribution, along with small subsidiary modes.

The small aberrant population on the tail toward lower values was found to mainly represent elutriate or biological samples mislabeled as sediments. The NOAA National Standards and Trends (NS\&T) data set (NST, 1996) plotted here for Cu (Fig. 3) also shows lognormal character, but has a much lower mean than the Boston Harbor data set. This data set was obtained from the Benthic Surveillance project, covering estuaries, harbors and coastal areas around the United States, and was chosen as a representative data set to demonstrate the general distribution of contaminant ratios.

\subsection{Concentration range screening}

Many problems with data quality can be found by inspection of samples having contaminant concentrations in the high and low ends of the range. Table 4 gives an example of such reference levels. Others could be used as appropriate to the area and constituents in question. The expected maximum and minimum data are mainly provided to provide guidelines to detect possible 'unreasonable' values due to correctible errors in unit designations. Table 5 shows a set of Boston Harbor sediments sorted on $\mathrm{Hg}$ in descending order, along with other metals. Values exceeding five times the 'ERM' toxicity screening values for metal toxicity in sediments (Long et al., 1995) are shaded. For historical data, supplementary laboratory or other tests for toxicity relationships pertinent to benthic organisms are not possible. However, bulk-sediment screening criteria or quality guidelines associated with concentration levels of contaminants have been found to offer conservative indexes of toxicity level.
Table 4

Concentration range guidelines for metals in bulk dry sediments

\begin{tabular}{|c|c|c|c|c|c|c|}
\hline Element & Soil & $\begin{array}{l}\text { SQAG } \\
\text { (ERL) }\end{array}$ & $\begin{array}{l}\text { SQAG } \\
(\mathrm{ERM})\end{array}$ & $\begin{array}{l}\text { Minimum } \\
\text { range }\end{array}$ & $\begin{array}{l}\text { Maximum } \\
\text { range }\end{array}$ & Ref. \\
\hline $\mathrm{Ag}$ & 0.05 & 1 & 3.7 & 0.02 & & \\
\hline $\mathrm{Al}$ & 71000 & & & 10000 & 100000 & $\mathrm{~N}$ \\
\hline As & 6 & 8.2 & 70 & 1 & & $\mathrm{~N}$ \\
\hline B & 20 & & & 5 & 150 & $\mathrm{~N}$ \\
\hline $\mathrm{Ba}$ & 500 & & & 50 & 1000 & $\mathrm{~N}$ \\
\hline $\mathrm{Be}$ & 0.3 & & & 0.1 & 10 & $\mathrm{~N}$ \\
\hline $\mathrm{Ca}$ & 15000 & & & 2000 & 100000 & $\mathrm{~N}$ \\
\hline $\mathrm{Cd}$ & 0.35 & 1.2 & 9.6 & 0.04 & & \\
\hline Co & 8 & & & 0.5 & 100 & $\mathrm{~N}$ \\
\hline $\mathrm{Cr}$ & 70 & 81 & 370 & 4 & & \\
\hline $\mathrm{Cu}$ & 30 & 34 & 270 & 1 & & \\
\hline $\mathrm{Fe}$ & 40000 & & & 2000 & & $\mathrm{~N}$ \\
\hline $\mathrm{Hg}$ & 0.06 & 0.15 & 0.71 & 0.01 & 0.71 & \\
\hline $\mathrm{K}$ & 14000 & & & 1000 & 40000 & $\mathrm{~N}$ \\
\hline $\mathrm{Mg}$ & 5000 & & & 2000 & 50000 & $\mathrm{~N}$ \\
\hline Mo & 1.2 & & & 0.5 & 25 & $\mathrm{~N}$ \\
\hline $\mathrm{Na}$ & 5000 & & & 3000 & 50000 & $\mathrm{~N}$ \\
\hline $\mathrm{Ni}$ & 50 & 20.9 & 51.6 & 3 & & \\
\hline $\mathrm{P}$ & 800 & & & 200 & 30000 & $\mathrm{~N}$ \\
\hline $\mathrm{Pb}$ & 35 & 46.7 & 218 & 2 & & \\
\hline S & 700 & & & 300 & 30000 & $\mathrm{~N}$ \\
\hline $\mathrm{Sb}$ & 1 & & & 0.1 & 25 & NST \\
\hline $\mathrm{Se}$ & 0.4 & & & 0.05 & 5 & NST \\
\hline $\mathrm{Si}$ & $\begin{array}{l}33000 \\
0\end{array}$ & & & 10000 & 480000 & $\mathrm{~N}$ \\
\hline $\mathrm{Tl}$ & 0.2 & & & 0.05 & 20 & NST \\
\hline $\mathrm{U}$ & 2 & & & 0.5 & 10 & NST \\
\hline V & 90 & & & 5 & 350 & NST \\
\hline $\mathrm{Zn}$ & 90 & 150 & 410 & 5 & & \\
\hline Corg & 20000 & & & 1000 & 50000 & $\mathrm{~N}$ \\
\hline Norg $(\mathrm{Kj})$ & 2000 & & & 200 & 5000 & $\mathrm{~N}$ \\
\hline
\end{tabular}

All values in are in $\mu \mathrm{g} / \mathrm{g}$.

Average for soil data (natural) is taken as most closely resembling uncontaminated estuarine sediments (from Bowen, 1979). SQAG refers to Sediment Quality Assessment Guidelines (Long et al., 1995).

ERL refers to Toxic Effects-Range Low, from Long et al., 1995. ERM refers to Toxic Effects-Range Medium, from Long et al., 1995.

$\mathrm{N}$ refers to references for maximum-minimum ranges range for normally non-toxic elements in natural sediments, based on standard geochemical summaries (Wedepohl, 1978; Bowen, 1979).

NST refers to a 'high' range for potentially toxic elements for which no SQAG or equivalent values are available, estimated from data in NOAA NST sediment monitoring sample database (NST, 1996).

The five highest (extreme) $\mathrm{Hg}$ values have concentration levels more than twenty times higher than the next highest data point. These values came from samples having other metal values that were below 
Table 5

Selected metal concentrations in the 1993 Boston Harbor sediment database, sorted on Hg in descending order. Shading denotes samples whose concentrations are more than five times the ERM toxicity level (column 4 in Table 4). Heavy borders delineate a Hg value believed to be erroneously carried down by the citing source from a $\mathrm{Cu}$ value in the original data resource. Light shading refers to values below the expected minimum range shown in Table 4

\begin{tabular}{|c|c|c|c|c|c|c|c|c|}
\hline UNIQUE_ID & LATITUDE & LONGITUDE & Source Code & CR_UG_G & CU_UG_G & HG_UG_G & PB_UG_G & ZN_UG_G \\
\hline US00008 & 42.385 & -71.04611 & 1 & 0.83 & 80 & 5760 & 1200 & 465 \\
\hline US00006 & 42.385 & -71.04611 & 1 & 1.9 & 260 & 3160 & 400 & 29.5 \\
\hline US00003 & 42.385 & -71.04611 & 1 & 1.2 & 200 & 2350 & 505 & 7.5 \\
\hline US00004 & 42.385 & -71.04611 & 1 & 2.4 & 250 & 1960 & 1100 & 86250 \\
\hline US00009 & 42.385 & -71.04611 & 1 & 1.4 & 47 & 1140 & 450 & 175 \\
\hline US02736 & 42.38416 & -71.04722 & 81 & 57.8 & 68.8 & 68.8 & 151.2 & 264 \\
\hline US01992 & 42.3675 & -71.04361 & 57 & 250 & 460 & 26 & 400 & 800 \\
\hline US02008 & 42.38666 & -71.04027 & 57 & 97 & 1650 & 23 & 2000 & 7200 \\
\hline US01983 & 42.35833 & -71.05 & 57 & 120 & 480 & 20 & 230 & 1100 \\
\hline US00306 & 42.35958 & -71.04805 & 26 & 68 & 408 & 14 & 805 & 59.6 \\
\hline US07693 & & & & 90 & 64 & 14 & 85 & 190 \\
\hline US00318 & 42.36072 & -71.049 & 26 & 28 & 75 & 12 & 244 & 283 \\
\hline US02705 & 42.34472 & -70.96527 & 81 & 136 & 75 & 12 & 77 & 210 \\
\hline US02149 & 42.30833 & -70.97638 & 67 & 302 & 192 & 9.4 & 234 & 242 \\
\hline US02714 & 42.35277 & -71.05138 & 81 & 195 & 218.2 & 9.4 & 500 & 595 \\
\hline US00308 & 42.3593 & -71.04905 & 26 & 44 & 627 & 8 & 1244 & 2156 \\
\hline US02687 & 42.31805 & -71.02166 & & 240 & 110 & 8 & 142.5 & 190 \\
\hline US00307 & 42.35941 & -71.04894 & 26 & 64 & 173 & 7 & 524 & 380 \\
\hline US02069 & & & & 451 & 338 & 6.8 & 222 & 410 \\
\hline US02159 & 42.34305 & -71.01388 & 67 & 133 & 81 & 6.8 & 84 & 160 \\
\hline US02162 & 42.35833 & -70.98472 & 67 & 134 & 292 & 6.8 & 84 & 160 \\
\hline US01507 & 42.30722 & -71.03694 & 48 & 128 & 108 & 6.7 & 117 & 183 \\
\hline US02068 & & & & 653 & 649 & 6.6 & 337 & 583 \\
\hline US01982 & 42.3575 & -71.05 & 57 & 250 & 390 & 6.5 & 310 & 950 \\
\hline US02163 & 42.36527 & -71.04861 & 67 & 418 & 339 & 6.3 & 402 & 506 \\
\hline US02153-1 & 42.32361 & -71.00555 & 67 & 292 & 239 & 6.1 & 215 & 317 \\
\hline US02157 & 42.33472 & -70.95972 & 67 & 255 & 239 & 6.1 & 215 & 317 \\
\hline
\end{tabular}

levels expected for naturally occurring (pristine) sediments in this area. One sample from this set also reported grossly anomalous $\mathrm{Zn}$ concentrations, without supporting evidence. It was clear from these and other indications that all metal data from the laboratory that had reported out these data should be flagged with warnings.

The sixth-highest $\mathrm{Hg}$ value $(68.8 \mu \mathrm{g} / \mathrm{g})$ suffered from another type of problem that occasionally occurs in secondary sources. This anomalous Hag value was carried down by mistake in a secondary compilation from a $\mathrm{Cu}$ value identified as an entry in the original data set. The originating laboratory reported a value of $1.2 \mu \mathrm{g} / \mathrm{g}$ in its primary records, in agreement with other well-controlled data for the area.

\subsubsection{Outliers}

Some comment is needed on range data with respect to outlier removal. Range data may be useful to remove outliers for determination of means and other statistical distributions. However, they are not sufficient to identify outliers related to data quality problems. A common range method to delineate as outliers utilizes the average less three times the standard deviation, or the average plus three times the standard deviation. The spread of the Boston Harbor data set is so large that the lower limit for all metals would extend to negative numbers. On the high side the $3 \times$ SD approach would fail to detect some problem data discussed in the next section but would discriminate against high-concentration data points deemed to be valid. Approaches using the geometric mean and deviation would be better but still yield unacceptable results. Multivariate statistics that take into account anomalies in more than one constituent are sometimes used to delineate outlier samples, rather than data. However, the spread of the data again tend to defeat such approaches for Boston Harbor sediments, and those in other impacted harbor environments. In short, establishing ranges is an important first step in evaluating the distribution of data, especially those in high (potentially toxic) or anomalously low concentration levels. But statistical measurements relating to ranges are insufficient guides to problem data.

\subsection{Ratio plotting and use of standard data sets: zinc normalization}

Contaminants often occur together because of common sources or chemical behaviors. Deviations 


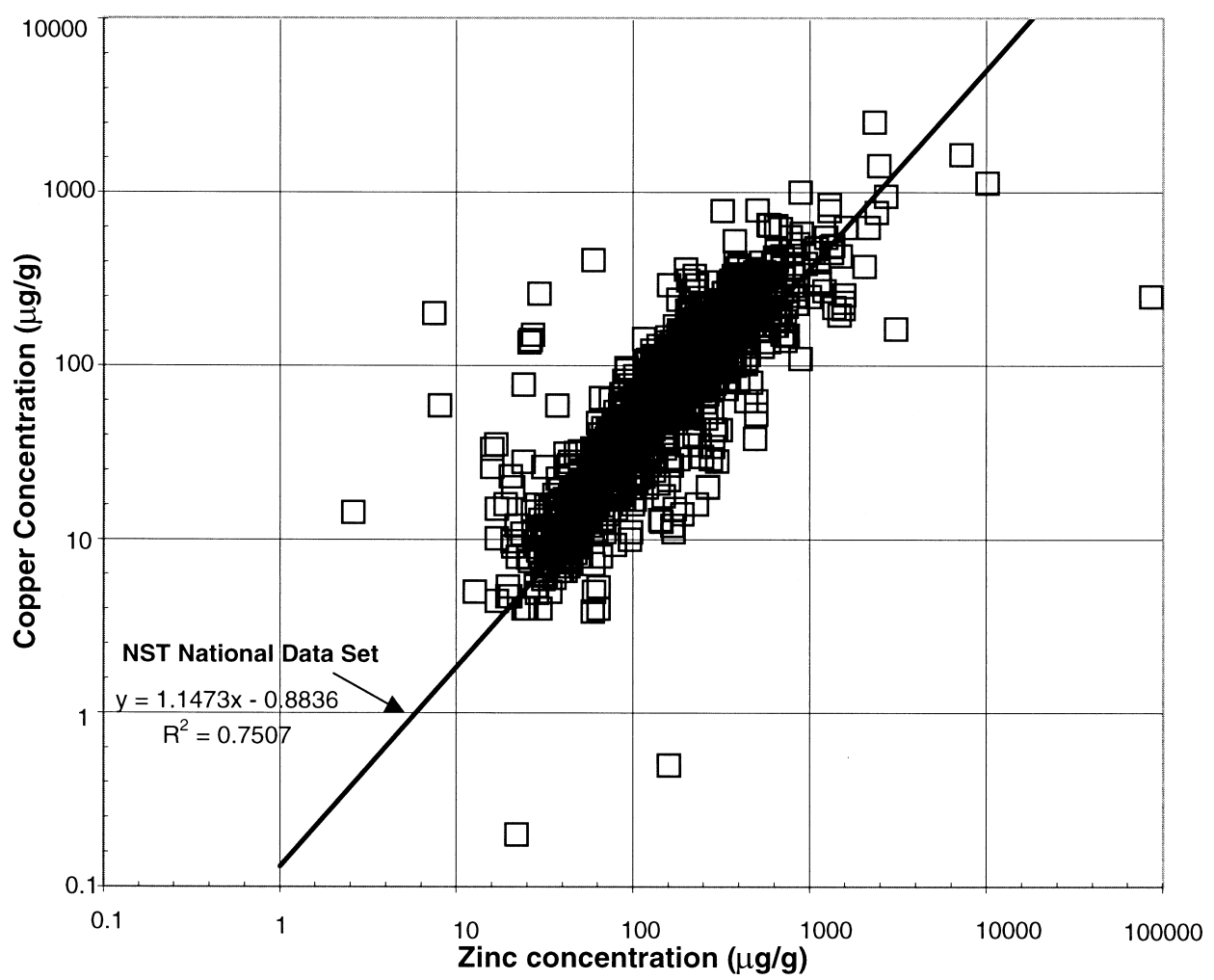

Fig. 4. Plot of $\mathrm{Cu}$ against zinc for the Boston Harbor-Massachusetts Bay data set. The regression line is for the NST data set (NST, 1994).

from typical associations can be used to further identify data quality. Plotting metals against $\mathrm{Zn}$ concentrations takes advantage of the fact that interelement ratios in contaminated sediments show much greater coherence than do the absolute concentrations of the components. As further elaborated in work in preparation, zinc is a suitable element for normalization, because it is almost always included in contaminant data sets, often displays the largest concentrations among the metals, and is a nearly ubiquitous marker wherever anthropogenic influences are present in waterways. As may be seen in Fig. 4, plotting $\mathrm{Cu}$ against $\mathrm{Zn}$ reveals a consistent relationship on a $\log / \log$ plot. The utility of such plots is increased by adding the regression line for large standardized data sets as a normalizing tool. Regressions for the NS\&T sediment data set (NST, 1996), compiled from hundreds of benthic monitoring stations, are incorporated in Figs. 4 and 5. Close agreement with the NS\&T regression line is not necessarily expected, but samples and groups of samples hav- ing a common source, which show large departures from local trends (e.g. more than a factor of about two) call for closer examination. If no factors or sources explaining the aberrant behavior are found, in conjunction with well-qualified data from similar environments, samples may be flagged as requiring further confirmation or potentially questionable.

Outlier points on such plots may be examined to determine if they are due to regional variations in contaminants, or due to systematic errors in analysis. Fig. 5, for $\mathrm{Hg}$ and $\mathrm{Zn}$, shows much greater scatter than does $\mathrm{Cu} / \mathrm{Zn}$. This is attributable, among other reasons, to the lower concentrations of $\mathrm{Hg}$, and greater diversity of sources than for $\mathrm{Cu}$ and $\mathrm{Zn}$. The aberrant data $\mathrm{Hg}$ data depicted in Table 5 may be seen scattered near the top of the foregoing figure.

\subsection{Organic contaminants}

$\mathrm{Log} / \log$ plots, as employed for metals, above, are critical to perform validation controls on or- 


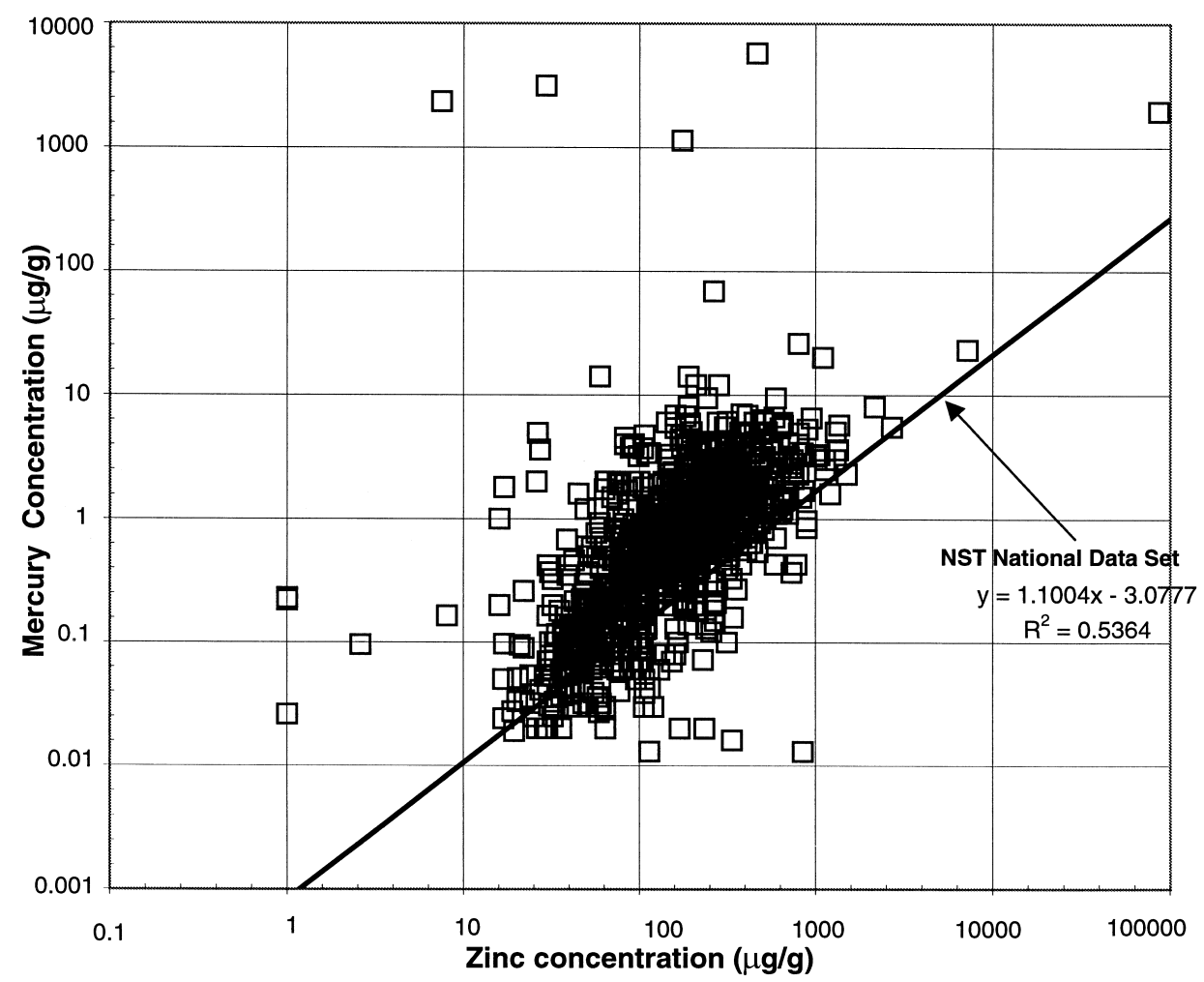

Fig. 5. Plot of Hg against zinc for the Boston Harbor-Massachusetts Bay database. The regression line is for the NST data set.

ganic contaminants. Fig. 6 shows a plot of polychlorinated biphenyl congeners for Boston HarborMassachusetts Bay samples (1994 cutoff date) for all data sources (656 samples). Of the 47 sources 25 were U.S. Army Corps of Engineers permit files with only a few data each. This plot of raw data reveals several types of information: (1) there is predictable increase in scatter toward lower values as data approach detection limits; (2) linear rows of data points in the vertical and horizontal directions for certain data sets signify detection limits that were reported as measured values; (3) 'Total PCB' (as reported) values tend to show more scatter than congeners for given geographical areas. Some Total PCB data plotted three orders of order of magnitude below the present regression lines for the three congeners because of incorrect unit designations. Points identified visually on a spreadsheet plot can be automatically identified with respect to data series and record number by clicking with the mouse on recent editions of spreadsheet software.
Mix-ups can occur because total PCB is frequently listed as $\mu \mathrm{g} / \mathrm{g}(\mathrm{ppm})$, whereas congeners are normally listed as ng/g (ppb), a 1000-fold concentration difference. Plots thus provide quick checks on unit consistency. Total PCB values reported from earlier dates are expected to have poorer correlation because of uncertainties relating to the compositions measured and the way these were computed.

Fig. 7 plots the PCB 101 and PCB 153 pair, using different symbols for five randomly chosen, wellqualified sources of data. The consistent agreement, except at very low values, can be partly attributed to the fact that extended organic congener analysis has become more widely available in the last ten years. Laboratories undertaking analysis of complex mixtures of specific congeners generally have considerable expertise and tend to follow consistent $\mathrm{QA} / \mathrm{QC}$ procedures. See, however, caution regarding regionally variable source factors, below.

Similar plots of homologues for the polyaromatic hydrocarbons are shown for the high molecular 


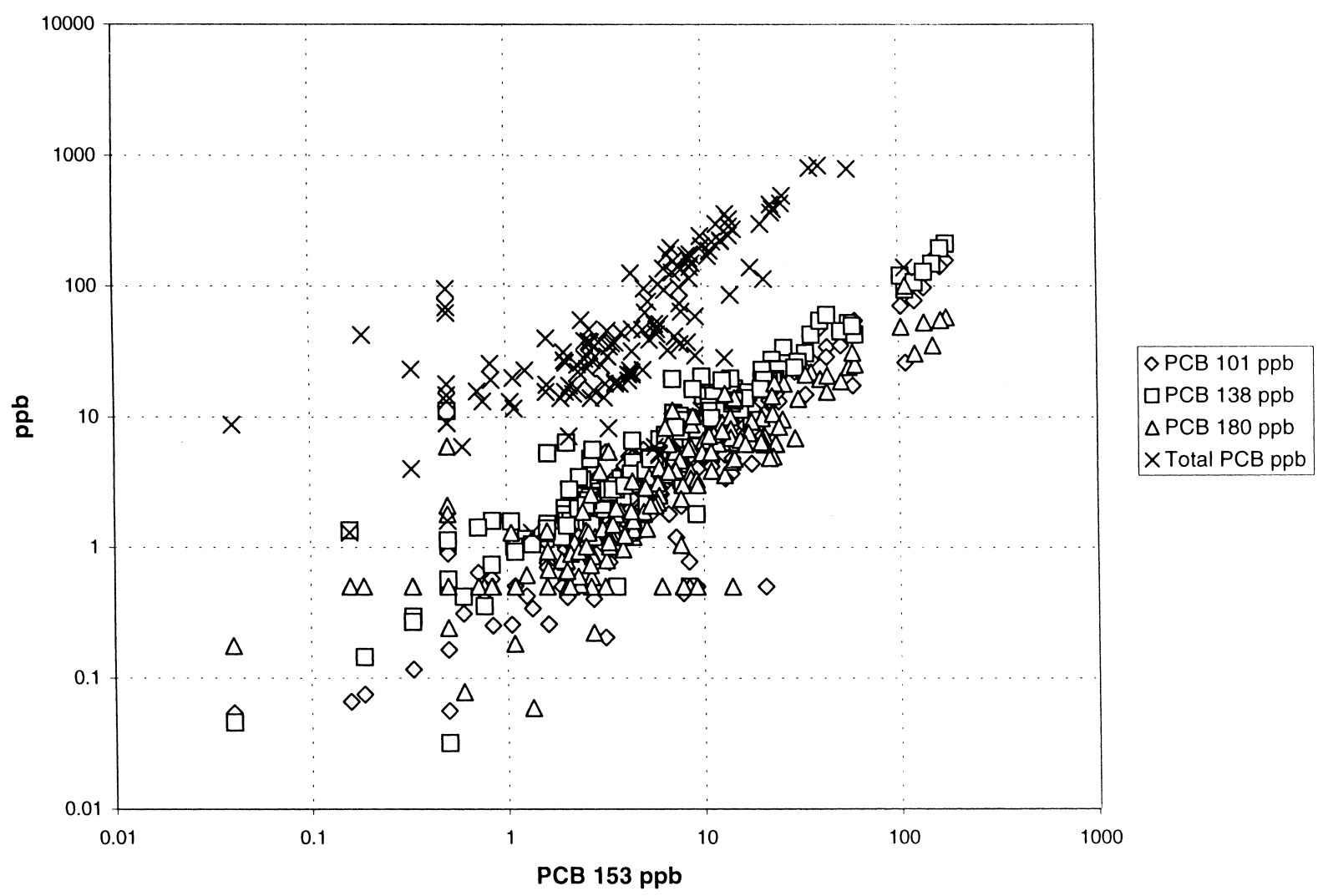

Fig. 6. Plot of PCB congeners for Boston Harbor-Massachusetts Bay data, all sources.

weight hydrocarbons (Fig. 8). Although phenanthrene is a 3-ring compound that nominally belongs to the light hydrocarbon group according to the NST (1994) delineation, it is closer to the heavier hydrocarbons in its behavior during uptake and weathering on sediments. It is particularly suitable as a normalizing component because it is often the most frequently observed PAH homologue.

Plotting for analytical consistency is ideally accomplished by using samples from similar areas, including samples from well-controlled laboratories. Once questionable data are identified, plotting may be useful for other diagnostic purposes, such as exploring questions of contaminant sources.

Plots of pesticide derivatives follow similar patterns. For example DDE 4,4' and DDD 4,4' are breakdown products of DDT, and much more widely detected than the latter in general sediments. They tend to show similar transport and weathering behaviors. These derivatives normally show good coher- ence in data from well-controlled data sources, and are therefore suited to assess analytical consistency among different sources of data. On the other hand, the chlordane group of pesticides remained in production well after DDT was prohibited in 1972. It may have a different time-distribution pattern as well as chemical affinities from DDT. In like fashion, one would first seek closely related pesticide species for data quality checking before utilizing ratios or other display of data that excludes questioned samples to explore for environmentally significant distributions of various pesticides.

\subsection{Texture normalization}

Normalization of data based on sediment grain size, carbon content, $\mathrm{Al}$ or $\mathrm{Fe}$ content or surface area has been frequently employed to reduce the effect of variable dilution by detrital minerals (Horowitz, 1991). We have not applied texture normalization 


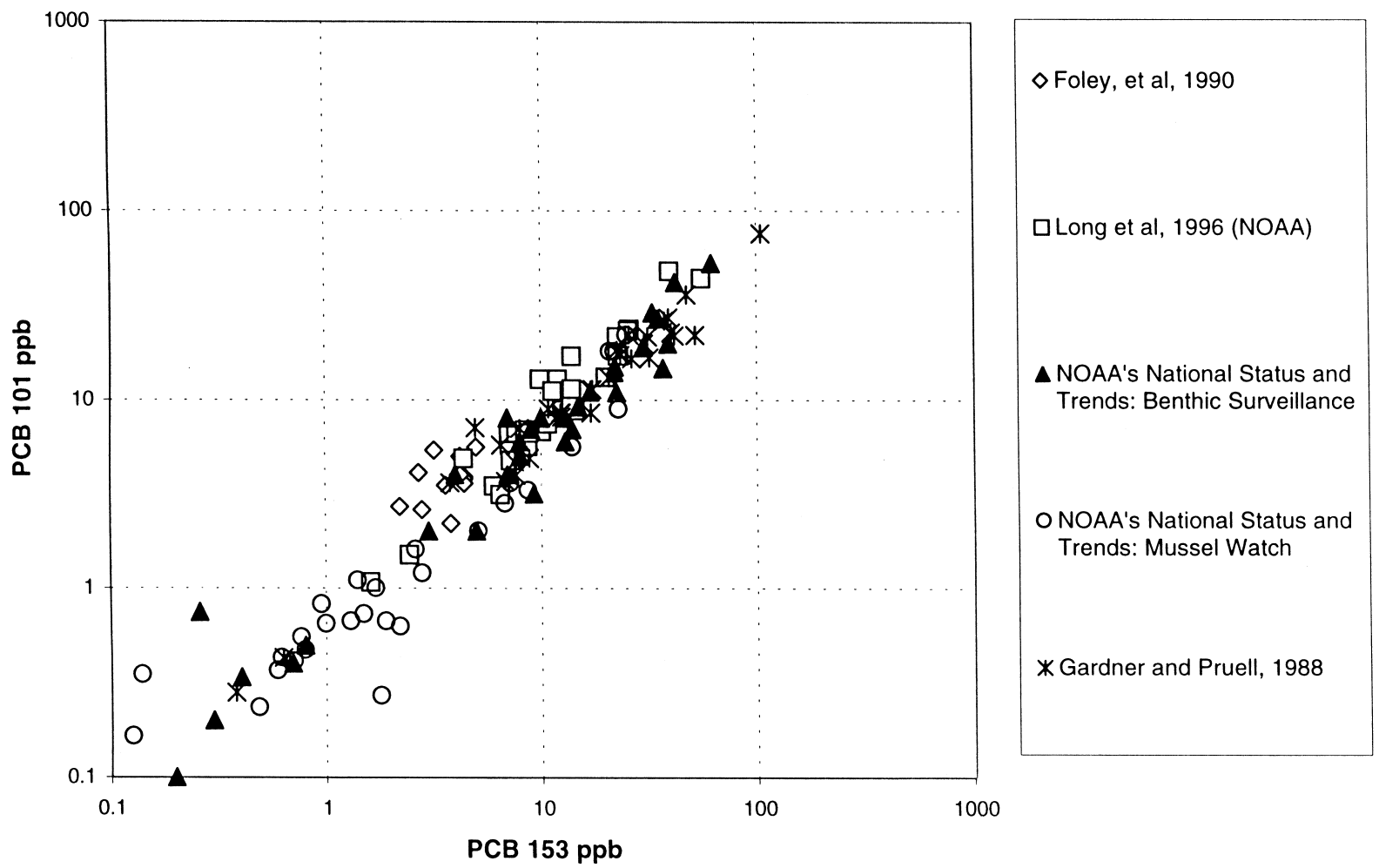

Fig. 7. Plot of PCB congeners 101 and 153 analyzed by five arbitrarily selected, well-controlled data sources: Foley et al., 1990 (diamonds); Long et al., 1996 (squares); NST, 1996 (triangles and circles); Gardner and Pruell, 1988 (asterisks).

to the sediments for several reasons. First, many of the heterogeneous data sets contained the only key pollutants and lacked normalizing metals. Variable analytical methodology also biases use of the more refractory metals (Al, Fe). Second, though in some areas contaminant levels correlate with texture or organic carbon, this relationship is not consistent. Normalization could potentially introduce significant error. Recent data (Bothner et al., 1997; L. Torres, unpublished information) suggest that part of the reason for this behavior is the past presence of localized point sources of contaminants, along with spatially heterogeneous natural sediment distribution in this glaciated area. One might point out in this context that the hard copy reports of the National Standards and Trends program have in the past reported 'mud' (silt plus clay) normalized data, whereas the data obtained by web site or floppy disc are unmodified.

\subsection{Spatial variability in composition}

Recent studies confirm that Boston Inner Harbor sediments have a high degrees of spatial variability in contaminant concentration, often within short distances, e.g. $200 \mathrm{~m}$. This effect is interpreted to be most pronounced in the center of the urban harbor complex. It is not due to unreliable data, as has sometimes been assumed. Rather, it reflects real heterogeneity, often associated with point contaminant sources and presence of CSOs. Such spatial inhomogeneity complicates the tracing of changes in bottom sediment quality with time through use of samples taken at different dates (Fig. 9). However, when sufficient samples are available to provide robust statistics, the aggregate effects are consistent with outer harbor studies of more homogeneously distributed sediments using dated cores (Bothner et al., 1997). They show decreases of 40 to $60 \%$ in $\mathrm{Cu}$, $\mathrm{Hg}$, and $\mathrm{Zn}$ concentrations in surficial sediments collected over a 17 -year period. A corollary conclusion 


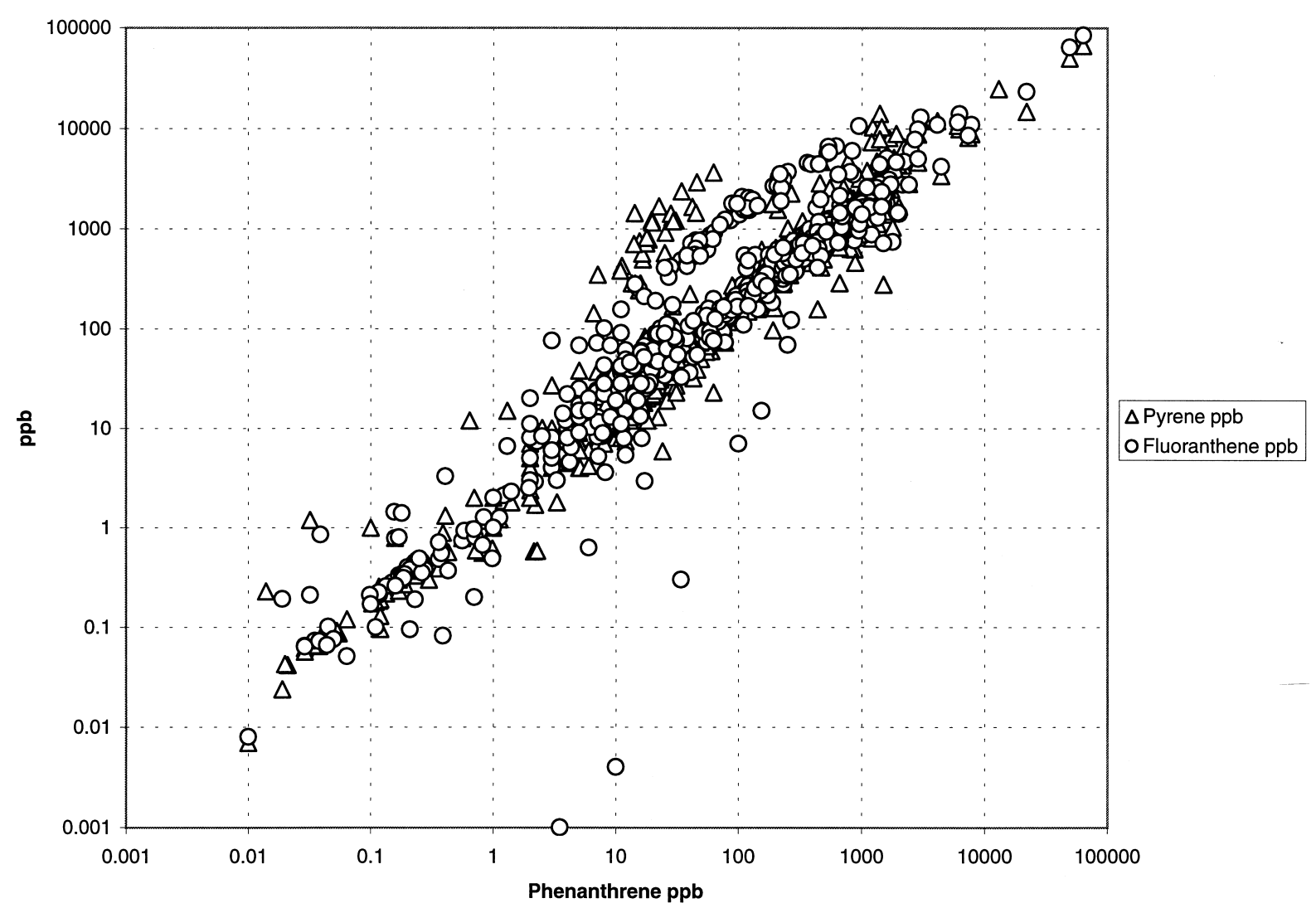

Fig. 8. Plot of two high-molecular weight PAH hydrocarbons against phenanthrene.

from the above observations would be that isolated cores within inner harbor environments may be expected to be much less representative of larger areas than areas of fine-grained sediment accumulations more distant from point sources.

\section{Summary and conclusions}

Assessment of a large, heterogeneous sediment data set from the Boston Harbor-Massachusetts Bay area has shown the following.

(1) Heterogeneous historical data can be successfully compiled even though data sources may lack specific information on the quality of analytical procedures. Comprehensive data rescue in Boston Harbor-Massachusetts Bay has greatly enhanced spatial resolution of contaminant distribution, helped identify sources, and helped document changes in the contaminant status of local environments with time. This kind of data rescue opens up large quantities of existing information to cost-effective use without new field studies.

(2) The study suggests that a relatively small fraction of the data, $<5 \%$ for zinc and copper in Boston Harbor-Massachusetts Bay, was associated with irremediable problems affecting their use for environmental assessment. A combination of editing for clerical errors, concentration range testing in spreadsheet format, and use of key geochemical relationships repair some data and reveal the presence of systematic errors consistent ways. Univariate or multivariate statistical methods by themselves are not reliable measures of outliers related to questionable analytical data. Ratio plots, regional groupings, and comparison with standard data sets serve as supplementary discriminant functions. Problematic data most often occur in batches from common sources or subsets. 

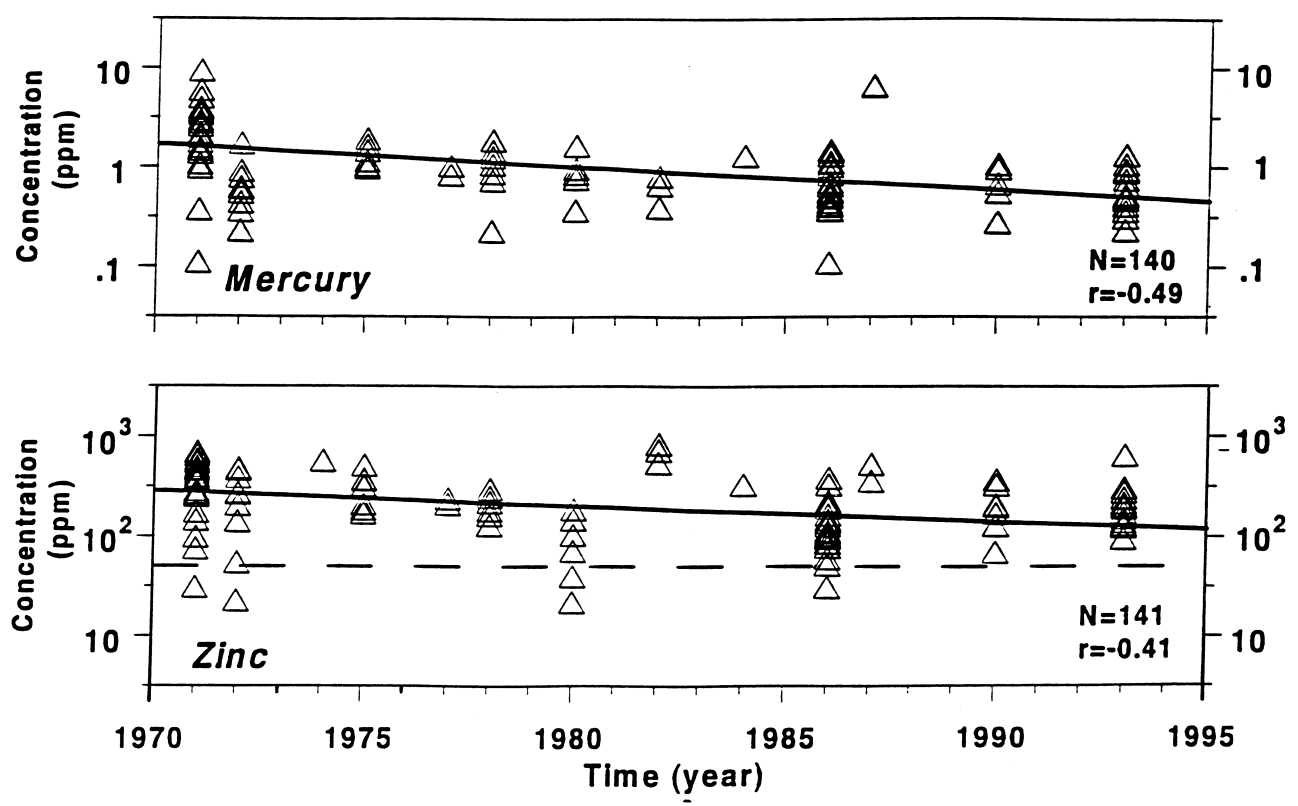

Fig. 9. Plot of surficial sediment samples from Boston Inner Harbor taken over time (modified from Bothner et al., 1997).

(3) All raw data are retained in the compiled database. The rationale for this policy includes the desirability of flagging potentially compromised data (which might otherwise be inadvertently or independently used for statistical or other characterization). Rejecting some data would require the setting of arbitrary criteria that might limit access of users to given data. It might also set up potentially unwarranted assumptions about the quality of retained data. Users have the ability and responsibility to set their own ultimate quality criteria. The authors and USGS take no responsibility for data other than those produced by USGS, except for exercising reasonable care in compiling information from their respective sources.

(4) Data rescue has revealed in more detail the presence of erratic distributions of contaminants in inner harbor environments. This potential must be considered in attempting modeling, averaging of data, or interpretations of cores from inner harbor areas.

\section{Acknowledgements}

We acknowledge the partial financial support of the Massachusetts Water Resources Authority toward studies reported here, and thank collaborators at the MWRA, U.S. EPA, U.S. Army Corps of Engineers and other local institutions for their cooperation and assistance. The analyses and cooperation of Michael Bothner have been of critical importance to this work. Finally, we acknowledge the assistance of Polly Hastings and Jamey Reid, who prepared many of the data sets and illustrations reported here.

\section{References}

Ahrens, L.H., 1954. The lognormal distribution of the elements (a fundamental law of geochemistry and its subsidiary). Geochim. Cosmochim. Acta 5, 49-73.

Baker, B., Kravitz, M. (Eds.), 1992. Sediment Classification Methods Compendium, Sediment Oversight Technical Committee. U.S. Environmental Protection Agency Report, EPA 823-R-92-006, chapter paginated, 14 chapters.

Bothner, M.H., Buchholtz ten Brink, M., Butman, B., Knebel, H.J., Manheim, F.T., Signell, R.P., 1994. Circulation and contaminant transport in Massachusetts Coastal Waters: a summary of achievements and future plans. U.S. Geol. Surv. Open-File Rep. 94-649, 30 pp.

Bothner, M.H., Buchholtz ten Brink, M., Manheim, F.T., 1997. Metal concentrations in surface sediments of Boston Harbor — changes with time. Mar. Environ. Res. 45, 127-155.

Bowen, H.J.M., 1979. Environmental Chemistry of the Elements. Academic Press, London, New York, 333 pp.

Buchholtz ten Brink, M.R., Manheim, F.T., Hathaway, J.C., 1992. 
Results of Boston Harbor Contaminated Sediment Database Development. Report on Cooperative database development with U.S. Army Corps of Engineers, New England District, 11 chapters and electronic media.

Butman, B., Bothner, M.H., Hathaway, J.C., Jenter, H.L., Knebel, H.J., Manheim, F.T., Signell, R.P., 1992. Contaminant transport and accumulation in Massachusetts Bay and Boston Harbor: a summary of United States Geological Survey studies in Massachusetts Bay. U.S. Geol. Surv. Open-File Rep. 92-202.

Edelstein, H., 1997. Data mining: exploiting the hidden trends in your data. DB2 Mag. 2: 19-23.

Foley, E., Bleczinski, C., Eustace, H., Howell, C., Kronick, A., O’Neill, S., Palmer, K., Wong, W., Rigatti, M., 1990. Final Data Report for evaluation of the reference site suitability for the Massachusetts Bay Disposal Site. Arthur D. Little, Inc., Cambridge, Massachusetts; prepared for the U.S. Environmental Protection Agency, Region I, Water Management Div., $25 \mathrm{pp}$.

Gardner, G.R., Pruell, R.J., 1988. A histopathological and chemical assessment of winter flounder, lobster and soft-shelled clam indigenous to Quincy Bay, Boston Harbor and an in situ evaluation of oysters including sediment (surface and cores) chemistry. Task II and III Report by U.S. Environment Protection Agency, Environmental Research Laboratory, Narragansett, Rhode Island, $80 \mathrm{pp}$. with tables and appendices.

Horowitz, A.J. 1991. A Primer on Sediment-Trace Elements Chemistry. Lewis Publishers, Chelsea, MI, 2nd ed., 136 pp.

Long, E.R., Morgan, L.G., 1990. The potential for biological effects of sediment-sorbed contaminants tested in the National Status and Trends Program, Seattle, WA. NOAA Tech. Mem., NOS OMA 62, 175 pp.

Long, E.R., MacDonald, D.D., Smith, S.L., Calder, F.D., 1995. Incidence of adverse biological effects within ranges of chemical concentrations in marine and estuarine sediments. Environ. Manage. 19, 81-97.

Long, E.R., Sloane, G.M., Carr, R.S.Ã., Scott, K.J., Thursby, G.B., Wade, T.L., 1996. Sediment toxicity in Boston Harbor: magnitude, extent, and relationships with chemical toxicants. NOAA Tech. Mem., NOS ORCA 96, 133 pp.

Manheim, F.T. (Ed.), 1993. Composition of contaminated sediments along the Atlantic Margin. Report by the USGS-Branch of Atlantic Marine Geology, Contaminated Sediments Project, to the U.S. Environmental Protection Agency National Contaminated Sediment Data Inventory, and Tetratec, Inc., Baltimore MD (Contractor), 7 chapters, 5 appendices and 8 floppy disks (mainly compressed files).

Manheim, F.T., Hathaway, J.C., 1991. Polluted sediments in Boston Harbor, Massachusetts Bay: progress report on the Boston Harbor Data Management File. U.S. Geol. Surv. OpenFile Rep. 91-331, 27 pp.

Manheim, F.T., Hathaway, J.C., Buchholtz ten Brink, M.R., 1992. Compiling sediment and pollutant data bases from the historical record: results of pilot studies from the Boston HarborMassachusetts Bay Program. Proc. EPA's Contaminated Sediment Management Forum, v. EPA 823-R-92-007, pp. 28-33.
Manheim, F.T., Flowers, G.C., McIntire, A.G., Marot, M., Holmes, C., 1997. Environmental geochemistry and sediment quality in Lake Pontchartrain: database development and review. Gulf Coast Assoc. Geol. Soc. 47, 337-349.

Mason, C., 1984. Unpublished memorandum and correspondence with Office of Program Support, U.S. Environmental Protection Agency, Region I; supplied by S. Curran, Massachusetts Coastal Zone Management Program, Boston, MA.

Metcalf and Eddy, 1984. Boston Harbor Data Management File, Electronic data file in SAS format, with supplementary hard copy bibliography. Prepared for the U.S. Environmental Protection Agency, Region I; coding incomplete; available from U.S. Environmental Protection Agency, Harbor Studies, JFK Building, Boston, MA, 02128.

MWRA, 1997. Massachusetts Water Authority Technical and Miscellaneous Reports. Unpublished list, 7 pp. (available from B. McCarthy, Environmental Quality Dept., MWRA, 100 First Ave., Boston MA, 02129).

NRC, 1989. Contaminated Marine Sediments: Assessment and Remediation. National Academy Press, Washington DC, 493 pp.

NRC, 1997. Contaminated Sediments in Ports and Waterways: Cleanup Strategies and Technologies. National Research Council, National Academy Press, Washington DC, 295 pp.

NST, 1994. Inventory of chemical concentrations in coastal and estuarine sediments. NOAA Tech. Mem., NOS ORCA 76, 66 pp.

NST, 1996. Analyses of sediment samples for the NOAA National Standards and Trends (NS\&T) monitoring program, described by: Lauenstein, G., Cantillo, A.Y., Sampling and analytical methods of the National Status and Trends Program, National Benthic Surveillance and Mussel Watch Projects, 1984-1992; web site http://www.orca.nos.noaa.gov/projects/ nsandt/nsandt.html.

O'Connor, T.P., 1990. Coastal environmental quality in the United States. A Special NOAA 20th Anniversary Report, 34 pp.

Scott, D. (Compiler), 1996. Massachusetts Bays Program Bibliography, Floppy disk with User's Guide. Massachusetts Bays Program, Boston, MA, 24 pp.; Cooperative venture of Massachusetts Coastal Zone Management Office and U.S. Environmental Protection Agency.

USEPA, 1995. QA/QC guidance for sampling and analysis of sediments, waters, and tissues for dredged material evaluations, prepared by Tetratec Inc. for the U.S. Environmental Protection Agency and U.S. Army Corps of Engineers. USEPA Report 823-B-95-001, chapter paginated, about 250 pp. in loose-leaf format.

USEPA, 1996. The National Sediment Quality Survey. A Report to Congress on the Extent and Severity of Sediment Contamination in Surface Waters of the United States. Draft, July 1996, United States Environmental Protection Agency, Office of Science and Technology, Standards and Applied Science Division, Washington DC, chapter paginated, 9 chapters.

Wedepohl, K.H. (Ed.), 1978. Handbook of Geochemistry. Springer Verlag, Berlin, Heidelberg, New York, Volumes I-V. 